\title{
Correction to: Analysis of socio- environmental impacts of the loss of urban trees and vegetation in Lahore, Pakistan: a review of public perception
}

Safdar Ali Shirazi ${ }^{i^{*}}$ and Jamil H. Kazmi

\section{Correction to: Ecol Process \\ https://doi.org/10.1186/s13717-016-0050-8}

In the original publication of this article (Shirazi et al., 2016) the author figured out that in the Fig. 1, the upper left corner Map of Pakistan was inappropriate as per the national policy. In map of Pakistan, Jammu \& Kashmir (occupied by India) must be shown annexed with Pakistan while mentioning Azad Jammu \& Kashmir as disputed territory.

Since map was prepared in mapping software (ArcGIS) developed by ESRI, USA, and this software shows Azad Kashmir as part of Pakistan while the Jammu \& Kashmir occupied by India is shown with the India by default.

Keeping in view the above facts, the author requested to replace the map in the article with the corrected map.

\section{Author details}

'Department of Geography, University of the Punjab, Quaid-i-Azam Campus, Lahore, Pakistan. 'Department of Geography, University of Karachi, Karachi, Pakistan.

Published online: 19 June 2019

\section{Reference}

Shirazi SA, Kazmi JH et al (2016) Analysis of socio-environmental impacts of the loss of urban trees and vegetation in Lahore, Pakistan: a review of public perception. Ecol Process 5:5. https://doi.org/10.1186/s13717-016-0050-8

\footnotetext{
* Correspondence: shirazi.geog@pu.edu.pk

The original article can be found online at https://doi.org/10.1186/s13717016-0050-8

'Department of Geography, University of the Punjab, Quaid-i-Azam Campus, Lahore, Pakistan

Full list of author information is available at the end of the article
} 


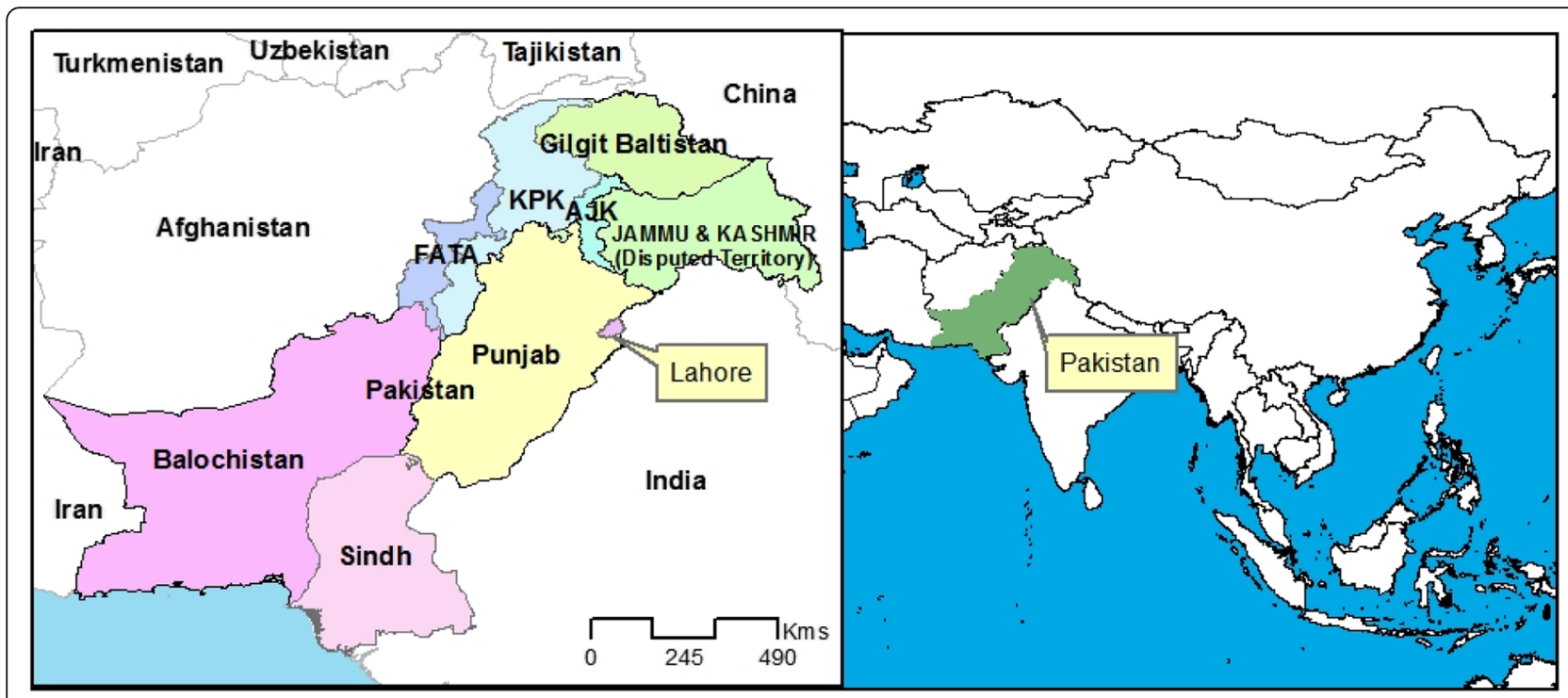

Fig. 1 Location map showing Lahore - the study area 